\title{
Um computador por aluno: possibilidades de inclusão e letramento digital
}

Jeronimo Becker Flores*

\section{Resumo}

\begin{abstract}
Neste artigo, desenvolve-se uma reflexão teórica na qual são abordadas questões como a educação no contexto das Tecnologias da Informação e Comunicação (TICs) e a inclusão digital. À luz do referencial teórico, trata-se de conceitos como alfabetização, inclusão e letramento digital. De acordo com a perspectiva aqui adotada, pondera-se que não basta à escola instalar computadores nos seus espaços; é preciso desenvolver uma concepção de uso. Do mesmo modo, considera-se que não basta apenas promover a alfabetização digital, sendo necessário desenvolver o letramento digital para que a inclusão digital de fato ocorra.
\end{abstract}

Palavras-chave: Educação. Tecnologias digitais. Letramento digital. Inclusão digital.

\section{Inclusão e letramento digital}

O advento das tecnologias digitais tem conferido sensíveis alterações em nossas atividades cotidianas. Desde operar um caixa eletrônico, realizar uma pesquisa na web, atender uma chamada ou jogar um game no celular, isso tudo nos faz perceber, diariamente, a constância das tecnologias digitais em nossas vidas. Trata-se de atividades corriqueiras para parte da população, mas que podem representar desafios, exclusão e falta de oportunidade para outra parcela, a dos excluídos digitalmente.

Essa exclusão atinge diversos setores da sociedade, inclusive a escola. Coscarelli e Ribeiro argumentam que "no Brasil, de maneira geral, principalmente no que se refere ao ensino público de base, podemos dizer que instituições, educadores, professores e alunos são excluídos digitalmente" (2005, p. 17).

\section{Recebido: 13/04/2013 - Aprovado: 31/06/2013 \\ http://dx.doi.org/10.5335/rep.2013.3558}

Graduado em Licenciatura Plena em Matemática pela Universidade de Caxias do Sul (2007), mestrando em Educação pela mesma instituição. Atualmente, é bolsista e pesquisador do CNPq, com pesquisas concentradas em tecnologias na educação. E-mail: jeronimobecker@gmail.com. 
É considerável a problemática intrínseca à exclusão digital, em especial em relação à escola, pois esta recebe alunos oriundos de uma sociedade marcada pela cultura digital, denominados por Prensky (2004) de nativos digitais. São caracterizados pelo pensamento em rede, um uso quase natural dos recursos tecnológicos digitais, com uma ampla abertura ao novo. Em contraponto, a escola parece permanecer engessada em um modelo analógico, repetindo antigas práticas, em uma dicotomia com o atual ritmo apresentado pela sociedade e pelos estudantes que esta gera.

Em busca da erradicação dessa problemática, observamos iniciativas, geralmente partindo do poder público, que visam a promover a inclusão digital. Porém, o que é de fato a inclusão digital? O que significa estar incluso digitalmente? Para Coscarelli e Ribeiro,

[...] inclusão digital é um processo em que uma pessoa ou grupo de pessoas passa a partilhar dos métodos de processamento, transferência e armazenamento de informações que são do uso costume de outro grupo, passando a ter os mesmos direitos e os mesmos deveres dos já participantes daquele grupo onde está se incluindo (2005, p. 17).

Inclusão digital não se relaciona apenas à disponibilização de computadores ou ao fornecimento de acesso à internet, mas implica proporcionar a chance de o sujeito partilhar dos mesmos direitos e deveres dos demais cidadãos já inclusos. Não se relaciona apenas a conhecer as práticas vigentes, mas implica contar com a possibilidade de interagir com elas, criticá-las e alterá-las. Para que isso seja possível, não basta disponibilizar a tecnologia, sendo indispensável o desenvolvimento de uma concepção crítica, competente e reflexiva de uso.

Ponderamos que o acesso à tecnologia é uma etapa significativa, porém não a única, para a inclusão digital. Muitas vezes, observamos iniciativas públicas visando à inclusão digital, mas que ficam restritas ao fornecimento de equipamentos, não cumprindo dessa maneira seu intuito inicial. Partimos do pressuposto de que a inclusão digital está atrelada a três elementos: acesso, condições de uso e letramento digital.

O acesso é o passo introdutório e, possivelmente, o mais perceptível, sobretudo a olhos dotados de pouca crítica. Denominamos essa etapa, assim como Coscarelli e Ribeiro (2005), de popularização ou democratização da tecnologia. Um uso instrumental, distribuindo cliques sem significação, não representa, necessariamente, partilhar dos mesmos direitos e deveres de grupos que já estejam imersos e incluídos na cultura digital.

Todavia, o acesso não deixa de ser um passo relevante. Segundo Takahashi et al. (2000), setores que não contam com o acesso à rede são prejudicados financeira e intelectualmente. Na visão dos autores, 
[...] do mesmo modo, regiões, segmentos sociais, setores econômicos, organizações e indivíduos são afetados diferentemente pelo novo paradigma, em função das condições de acesso à informação, da base de conhecimentos e, sobretudo, da capacidade de aprender e inovar (2000, p. 5).

Nessa perspectiva, dificuldades nas condições de acesso podem excluir determinados grupos em relação a outros. $\mathrm{O}$ acesso pode reduzir as distâncias e aumentar o nível de informação da população. Contrapomos os argumentos dos autores, ponderando que, mesmo com acesso, mas sem uma concepção de uso, regiões e sujeitos permanecem excluídos digitalmente, mesmo possuindo computadores.

Apesar da relevância, possibilitar o acesso não é a condição final para que a inclusão digital ocorra plenamente. $\mathrm{O}$ uso das tecnologias pode ocorrer de forma mecânica, sem significado, o que não faz que o sujeito esteja de fato incluído na cultura digital. Um computador pode, perfeitamente, substituir a caneta, a máquina de escrever, a carta escrita, a calculadora, dentre outros recursos que independem da tecnologia digital. No entanto, essa substituição não representa mudança alguma no contexto social ou cognitivo dos usuários. São necessárias ações que visem às concepções e condições de uso. De acordo com Coscarelli e Ribeiro,

[...] é preciso ir muito além do aprender a digitar em um computador. Quando as pessoas em situação de exclusão social passam a ter acesso ao computador e seus recursos, pode-se falar em popularização ou mesmo em democratização da informática, mas não necessariamente em inclusão digital (2005, p. 15).

Desse modo, promover a inclusão digital não corresponde a apenas fornecer computadores e promover o acesso à internet, mas a desenvolver uma reflexão sobre a ação no contexto digital. Hargreaves (2004) critica o modo como nos relacionamos com as tecnologias hoje em dia. Segundo o autor, embora nos ofereça uma vasta gama de informações, a web não traz critérios éticos, intelectuais ou morais de seleção. Esses critérios são desenvolvidos pelo sujeito, na reflexão e na crítica sobre o uso da tecnologia. A escola pode contribuir nesse sentido não só possibilitando o acesso aos computadores como também construindo uma base de pensamento crítico sobre a ação no contexto digital. Infelizmente, esses aspectos parecem ser ignorados por parte das escolas contemporâneas.

Ponderamos, ainda, que são errôneas as ações que visam a promover a inclusão digital por intermédio apenas da alfabetização digital. De acordo com Soares (1998, 2002), existem claras distinções entre alfabetização e letramento. A alfabetização relaciona-se ao conhecimento básico do código, à articulação entre o símbolo e o signo. Já o letramento apresenta uma relação entre as práticas de leitura e escrita realizadas em uma esfera social, na leitura e na alteração do contexto no qual o sujeito está incluído. A autora entende o letramento como 
sendo não as próprias práticas de leitura e escrita, e/ou os eventos relacionados com o uso e função dessas práticas, ou ainda o impacto ou consequências da escrita sobre a sociedade, mas, para além de tudo isso, o estado ou condição de quem exerce práticas sociais de leitura e escrita (SOARES, 2002, p. 145, grifo do autor).

Seguindo essa linha argumentativa, a alfabetização digital relaciona-se ao conhecimento básico da informática. Já o letramento digital vincula-se ao uso desses conhecimentos em uma esfera social, na leitura e na alteração da realidade na qual o sujeito está imerso. Buzato define o letramento digital como

conjuntos de letramentos (práticas sociais) que se apoiam, entrelaçam e apropriam mútua e continuamente por meio de dispositivos digitais para finalidades específicas, tanto em contextos socioculturais geograficamente e temporalmente limitados, quanto naqueles construídos pela interação mediada eletronicamente (2006, p. 16).

O letramento digital está relacionado às práticas sociais realizas sob a chancela do suporte digital. $\mathrm{O}$ fenômeno não ocorre de forma linear, de uma forma predefinida, mas de uma forma rizomática, espalhando-se em distintas direções. As práticas não ocorrem de maneira isolada, mas conjuntamente, em uma relação de apoio mútuo.

Ponderamos que, para a efetivação da inclusão digital, não basta ao sujeito estar alfabetizado digitalmente; ele precisa ser letrado digitalmente. A escola pode contribuir no fomento ao letramento digital, intermédio de ações que desenvolvam uma concepção de uso das tecnologias, como recurso de socialização, de entendimento e de alteração do mundo. Na próxima seção, trataremos de um exemplo de ação educacional passível de promover o letramento e a inclusão digital, por intermédio da aproximação entre estudantes e tecnologia, desenvolvendo concepções críticas e reflexivas em detrimento de um uso instrumental.

\section{Um computador por aluno - aproximando estudantes da cultura digital}

A sociedade segue um ritmo influenciado pela cultura digital, com dinamismo, velocidade e cruzamento de informações. À parte disso, a escola parece permanecer no modelo estático, analógico, marcado pela linearidade. Em busca de equacionar essa dicotomia e, também, de democratizar o acesso à tecnologia, observamos ações que visam a incluir a escola digitalmente.

De um modo geral, essas ações acabam por não cumprir seu objetivo inicial, por se limitarem ao acesso, ignorando os demais passos necessários à inclusão digital. Em muitos momentos, as ações restringem-se à instalação de laboratórios de informática educativa (LIE), no modelo "um computador para muitos". Os LIEs, geralmente, são estruturas apartadas da conjuntura da escola, exigindo dos 
professores procedimentos burocráticos, como o preenchimento de formulários e o agendamento prévio.

A concepção pedagógica de uso do LIE também é um assunto problemático. Muitas vezes, os professores utilizam o laboratório de informática como premiação ou punição para turmas com bom ou mau comportamento, segundo sua ótica. Além disso, podemos observar aulas de informática ministradas por técnicos em informática, que podem compreender questões de ordem técnica, mas que ignoram aspectos didáticos e pedagógicos em relação ao uso dos computadores.

Esses fatos acabam por não incluir a escola na cultura digital, mesmo que dentro dela existam computadores. O uso torna-se mecânico, sem significado, representando apenas um modismo tecnológico. Um uso sem significado, sem crítica e reflexão não representa inclusão digital.

O Programa Um Computador por Aluno (Prouca) oferece uma possibilidade diferente na relação entre sujeito e tecnologia. A proposta consiste no fornecimento de um laptop educacional para cada estudante (modelo 1:1), estrutura de apoio e formação para gestores e professores envolvidos por intermédio de parcerias com Instituições de Ensino Superior (IES).

Um dos diferenciais entre o Prouca e outras propostas está na proximidade entre estudante e tecnologia. O modelo 1:1, no qual cada estudante tem o seu laptop, com softwares voltados para o contexto educacional, representa uma relação distinta entre o sujeito e a tecnologia. Algumas escolas envolvidas permitem o traslado do equipamento do estudante para a sua residência. Assim, a abrangência do programa ultrapassa os muros da escola, podendo representar uma chance de inclusão digital para as famílias e os círculos de amizades dos atendidos.

Outro diferencial está na formação e capacitação de docentes e gestores envolvidos. Docentes e pesquisadores das IES parceiras desenvolvem uma formação continuada, pautada pela criticidade e pela reflexão sobre a ação. Os momentos de formação ocorrem de forma bimodal, ou seja, alternando momentos presenciais e a distância. A formação continuada é um dos pressupostos básicos para a participação das escolas no programa. Efetivamente, não existem garantias de que a formação irá resultar em alterações nas práticas pedagógicas do professor. Assim como fala Perrenoud, "formar-se não é - como uma visão burocrática poderia, às vezes, fazer crer - fazer cursos (mesmo ativamente); é aprender, é mudar, a partir de diversos procedimentos pessoais e coletivos de autoformação" (2000, p. 160).

$\mathrm{Na}$ concepção do autor, a formação relaciona-se a mecanismos individuais de subjetivação, envolvendo reflexão e criticidade, dependendo de uma postura ativa. Mesmo sem garantias dos resultados das formações, ponderamos que, contrariando outras iniciativas, o Prouca também concentrou seu olhar para a formação da equipe envolvida. 
Assim, esse programa não visou apenas a disponibilizar computadores, mas também a desenvolver uma concepção de uso, capacitando gestores e professores para uma atuação articulada com o contexto da cultura digital. Esse tipo de atuação tende a promover, mais do que a alfabetização, o letramento digital. Com uma equipe pedagógica capacitada, as aulas tendem a ganhar um contorno distinto do instrumental, relacionado ao uso. A criticidade, a reflexão e um uso competente são elementos que permeiam as formações docentes, podendo adentrar e produzir reflexos nas aulas. A proximidade com a tecnologia, o fato de levar o laptop para casa, uma equipe capacitada podem representar maiores chances de letramento e, consequentemente, de inclusão digital.

\section{Considerações para futuros debates}

No decorrer das discussões teóricas tratadas neste artigo, percebemos a relevância de se proceder a outras pesquisas e experiências em relação à educação no contexto das tecnologias digitais.

Observamos que existem iniciativas, possivelmente bem intencionadas, que inserem computadores nas escolas, sem promoverem uma discussão sólida sobre o uso, ou sem oferecer uma possibilidade de formação à equipe envolvida. Consideramos esse tipo de ação como inócua, pois não é apenas a tecnologia que representa a diferença, e sim a relação estabelecida entre esta e o homem. Desse modo, a instalação de computadores na escola pode não representar inovação alguma, reprisando um modelo de educação já existente, centrado na transmissão vertical de informações.

A burocracia e o afastamento dos computadores da sala de aula, fato observado em ações no modelo um computador para muitos, como ocorre, por exemplo, nos LIEs, tendem a não promover a inclusão digital. Os fatores citados tendem a dificultar o uso, levando a que o professor não utilize os computadores, ou, então, faça o uso sem uma proposta pedagógica.

A utilização da tecnologia digital sem significação e reflexão não é suficiente para promover a inclusão digital. Esse tipo de proposta pode instrumentalizar os sujeitos, fazendo que teclem e distribuam cliques aleatórios, utilizando, mas não interagindo de forma crítica no contexto digital.

Iniciativas como o Prouca, no qual os computadores ficam próximos do contexto escolar, podendo ser usado nas demandas cotidianas da sala de aula, tendem a aproximar mais o estudante do cenário digital. A formação do professor, nesse sentido, é um elemento muito relevante, pois pode levá-lo a adotar uma prática 
pedagógica que não veja o computador como uma mera ferramenta, e sim como um recurso para auxiliar na sua prática pedagógica.

Para ampliar as possibilidades do desenvolvimento do letramento digital, essa formação deve ser pautada pela criticidade, pelo diálogo e pela reflexão sobre a ação. Desse modo, formar um professor reflexivo parece ser mais adequado para as atuais demandas da cultura digital. Na perspectiva de Alarcão, "a noção do professor reflexivo baseia-se na consciência da capacidade do pensamento e reflexão que caracteriza o ser humano como criativo e não mero reprodutor de ideias e práticas que lhe são exteriores" (2007, p. 41).

A formação reflexiva está relacionada à reflexão sobre a ação, à tomada de consciência e ao redimensionamento da prática em vista da realidade. Uma formação docente com esse cunho tende a desenvolver uma capacidade crítica, conferindo ao professor possibilidades de questionamento aos cenários do contexto digital.

Uma formação docente marcada pela atitude reflexiva tende a fomentar uma concepção de uso das tecnologias digitais não como ferramentas, mas como recursos para o auxílio à prática pedagógica que podem ser questionados, alterados e criticados. Os estudantes orientados por professores formados continuamente podem desenvolver não apenas a alfabetização como também o letramento digital.

Um sujeito letrado digitalmente usa as tecnologias digitais de forma social e competente, com uma concepção crítica e reflexiva. Ou seja, partilha dos mesmos direitos e deveres daqueles que já participam da sociedade influenciada pela cultura digital, estando inclusos digitalmente.

\section{One computer per student: possibilities for inclusion and digital literacy}

\section{Abstract}

In this paper, we develop a theoretical reflection where we address issues such as education in the context of the Information and Communication Technologies and digital inclusion. The light of the theoretical framework, we deal with concepts such as literacy, digital literacy and inclusion. From the perspective we adopt, we ponder that it is not sufficient to school install computers in their spaces, it is necessary to develop a conception of use. Similarly, we ponder that is not enough just to promote digital alphabetization, it is necessary to develop the digital literacy in order to digital inclusion actually occurs.

Keywords: Education. Digital technologies. Digital literacy. Digital inclusion. 


\section{Referências}

ALARCÃO, I. Professores reflexivos em uma escola reflexiva. 5. ed. São Paulo: Cortez, 2007.

BUZATO, M. E. K. Letramento e inclusão na era digital. IEL/UNICAMP. Campinas, SP, 2006. Mimeografado.

COSCARELLI, C. V.; RIBEIRO, A. E. (Orgs.). Letramento digital: aspectos sociais e possibilidades pedagógicas. Belo Horizonte: Ceale; Autêntica, 2005.

HARGREAVES, A. O ensino na sociedade do conhecimento: educação na era da insegurança. Porto Alegre: Artmed, 2004.

PERRENOUD, P. Dez novas competências para ensinar. Trad. de Patrícia Chittoni Ramos. Porto Alegre: Artes Médicas Sul, 2000.

PRENSKY, M. The emerging online life of the digital native: what they do differently because of technology and how to they it. 2004. Disponível em: <www.markprenky.com/writing/ PrenskyThe_Emerging_Online_Life_of_the_Digital_Native-03:pdf:>. Acesso em: 20 jun. 2012.

SOARES, M. Letramento: um tema em três gêneros. Belo Horizonte: Autêntica, 1998.

Novas práticas de leitura e escrita: letramento na cibercultura. 2002. Disponível em: <http://www.cedes.unicamp.br>. Acesso em: 24 jun. 2011.

TAKAHASHI, T. (Org.). Sociedade da informação no Brasil: livro verde. Brasília: Ministério da Ciência e Tecnologia, 2000. 